rev Psi

Revista de Psicología (UNLP)

https://revistas.unlp.edu.ar/revpsi

\title{
Variedades de la letra y objetos autísticos
}

\author{
Éric Laurent ${ }^{1,2}$ \\ Correspondencia \\ ericlaurent@lacanian.net \\ Traducción y corrección de estilo \\ Traducción: Luis H. Volta | Corrección de estilo: Nicolás Alessandroni, María Cristina Piro
}

\section{Filiaciones institucionales}

${ }^{1}$ Asociación Mundial de Psicoanálisis (AMP) $\quad{ }^{2}$ Université Paris 8 Vincennes - Sant-Denis (Francia)

\section{Resumen}

Para responder a la variedad de sujetos dentro del espectro autista y a la diversidad de lugares que los reciben y que prestan atención al baño de lenguaje en el que esos sujetos están sumergidos, la orientación de nuestro trabajo apunta a definir la posición de un terapeuta partenaire respetuoso de los múltiples aspectos que puede tomar el efecto transformador de un encuentro nuevo con la lengua. Desde esta perspectiva, más que de la búsqueda de un método ideal para el abordaje del sujeto con autismo, se trata de presentar aquí la diversidad de resultados obtenidos en contextos de lo más variados cuyo rasgo constante es sostener el esfuerzo de inscripción del sujeto en todas las dimensiones de la lengua, de la instancia de la letra y del tratamiento de los objetos fuera del cuerpo tales como la mirada y la voz, en la gran variedad de situaciones o de talleres posibles, manteniendo al mismo tiempo los aprendizajes (fragmento del manuscrito).

\section{Palabras clave}

autismo | psicoanálisis | variedades de la letra | objetos autísticos

\section{Cómo citar}

Laurent, É. (2021). Variedad de la letra y objetos autísticos. Revista de Psicología, 20(1), 8-21. HTTPS://DX.DOI.ORG/10.24215/ 2422572 XE 113

\begin{tabular}{|c|c|}
\hline \multicolumn{2}{|c|}{ Proceso editorial } \\
\hline Recibido & 1ra decisión \\
\hline 4 may. 2021 & 23 jun. 2021 \\
\hline Aceptado & Publicado \\
\hline 23 jun. 2021 & 31 jul. 2021 \\
\hline
\end{tabular}

Coordinadora del dossier

María Cristina Piro (Facultad de Psicología UNLP, Argentina)
ISSN

2422-572X

Licencia

Licencia de Cultura Libre CC-BY 4.0

(Compartir - Adaptar - Atribuir)

Entidad editora

RevPsi es una publicación de la

Facultad de Psicología (Universidad

Nacional de La Plata, Argentina) 


\section{Variedades da letra e objetos autisticos}

\section{Resumo}

A fim de responder à variedade de sujeitos dentro do espectro autista e à diversidade de lugares que os recebem e prestam atenção ao banho de língua em que esses sujeitos estão imersos, a orientação de nosso trabalho visa definir a posição de um terapeuta que seja um partenaire respeitoso dos múltiplos aspectos que o efeito transformador de um novo encontro com a língua pode tomar. Nesta perspectiva, em vez de buscar um método ideal para a abordagem do sujeito autista, o objetivo é apresentar aqui a diversidade de resultados obtidos nos mais variados contextos, cuja característica constante é sustentar o esforço de inscrever o sujeito em todas as dimensões da linguagem, da instância da letra e do tratamento de objetos fora do corpo como o olhar e a voz, na grande variedade de situações ou oficinas possíveis, mantendo o processo de aprendizagem (fragmento do manuscrito).

\section{Palavras-chave}

autismo | psicanálise | variedades da letra | objetos autisticos

\section{Varieties of the letter and autistic objects}

\section{Abstract}

In order to respond to the variety of subjects within the autistic spectrum and the diversity of settings that receive them and pay attention to the language bath in which these subjects are immersed, our work aims at defining the position of a partenaire therapist who respects the multiple aspects that the transforming effect of a new encounter with language can take. From this perspective, rather than searching for an ideal method for the approach of the autistic subject, we present a diversity of results obtained in varied contexts whose constant feature is to sustain the effort of inscribing the subject in all the dimensions of language, the instance of the letter and the treatment of objects outside the body -such as the gaze and the voice-, in a great variety of situations and workshops, while maintaining the learning process (fragment of the manuscript).

\section{Keywords}

autism | psychoanalysis | varieties of the letter | autistic objects 
Para responder a la variedad de sujetos dentro del espectro autista y a la diversidad de lugares que los reciben y que prestan atención al baño de lenguaje en el que esos sujetos están sumergidos, la orientación de nuestro trabajo apunta a definir la posición de un terapeuta partenaire respetuoso de los múltiples aspectos que puede tomar el efecto transformador de un encuentro nuevo con la lengua.

Desde esta perspectiva, más que de la búsqueda de un método ideal para el abordaje del sujeto con autismo, se trata de presentar aquí la diversidad de resultados obtenidos en contextos de lo más variados cuyo rasgo constante es sostener el esfuerzo de inscripción del sujeto en todas las dimensiones de la lengua, de la instancia de la letra y del tratamiento de los objetos fuera del cuerpo tales como la mirada y la voz, en la gran variedad de situaciones o de talleres posibles, manteniendo al mismo tiempo los aprendizajes.

La serie de las máquinas sobre las cuales los sujetos autistas se han apoyado para construir su mundo es muy extensa. Incluye el aparato fotográfico del cual se sirvió Garance para construir su relación con "el espacio que no se ve" (Reliquet y Reliquet, 2011, p. 98; Laurent, 2012, p. 83), la computadora que ayudó a Birger Sellin para su comunicación asistida, el programa de reconocimiento vocal Siri para Gus (Newman, 2014) y el juego Minecraft para muchos. Pronto van a agregarse a esta una adaptación de anteojos de Google provistos de un programa de reconocimiento de rostros y de emociones desarrollados por un investigador de Stanford - en principio para su primo autista, quien practicaba el reconocimiento de emociones frente a su espejo (Metz, 2019) -, así como diversos robots neohumanos o neo-animales (Chérel, 2019).

Sin embargo, no se trata de reducir estos sujetos a "niños máquinas" y de creer que son puras computadoras. Estos sujetos tienen un cuerpo, y es ese cuerpo que tienen el que se encuentra sumergido en un baño de lenguaje. Es el lenguaje el que resulta ser la primera máquina encontrada por esos cuerpos y en la cual el viviente debe encontrar cómo alojarse. Con su sinestesia, Daniel Tammet se encuentra bien ubicado para decirnos que lo que experimenta al calcular no puede ser captado por ninguna máquina de Turing. Es necesario interesarse por la utilización de las máquinas como "asistentes del sujeto", sin por eso reducir el sujeto-cuerpo a una máquina. Es lo que permite tener en cuenta el encuentro con el lenguaje, que deja marcas "traumáticas" para todo sujeto que nace al lenguaje, hable o no. Este es el verdadero "trauma del nacimiento" y toma para el sujeto autista formas particulares. Las máquinas ponen en valor la multiplicidad de los registros que nosotros llamamos la letra, otro nombre de lo que funciona como uno a través de lo que llamamos hablar, escribir, contar o representarse una imagen.

\section{Variedades de la letra. El ejemplo de la Terapia de afinidad}

Partamos del testimonio de los esfuerzos de la familia de Ron Suskind para tratar el autismo de su hijo, publicado bajo el título de Life: Animated [Vida: animada] 
(Suskind, 2016 ${ }^{1}$. El relato de Cornelia y Ron Suskind es fascinante en tanto experiencia de una batalla por parte de la familia para inventar una lengua y un método a partir de un interés específico del niño. Este libro tuvo tal eco que dio lugar numerosas entrevistas y generó resonancias en numerosas personas. Me referiré a algunos momentos clave. En principio, la primera interpretación de Cornelia a mediados de los años 1990, cuando acababan de mudarse a Washington D.C. donde Ron había sido contratado como periodista a cargo de la política interior [national affairs] en el Wall Street Journal.

Simplemente tímido hasta su tercer cumpleaños, Owen desarrolló una forma de autismo regresivo, lo que significa que esencialmente dejó de comunicarse. Algo que siempre le gustaba era mirar los dibujos animados de Disney con su hermano. Miraba las mismas escenas una y otra vez (...) Luego, un día, mirando La sirenita, Owen dijo su primera palabra después de mucho tiempo: " juicervose". Su madre, Cornelia, comprendió que estaba diciendo "just your voice" [sólo tu voz], palabra surgida de una canción que Úrsula, la bruja del mar, le canta a la sirena Ariel. La familia interpretó esto como un signo de que Owen buscaba recuperar su voz. A partir de allí, los diálogos de Disney se volvieron la lengua que la familia Suskind utilizó para comunicarse con Owen, literalmente, hablándose unos a otros a través de la voz de diferentes personajes para expresar las cuestiones de la vida cotidiana. (Rosin, 2014, s/p; la traducción es mía)

Otra reseña del desarrollo de los usos de Owen del diálogo de Disney destaca los momentos de novedad, de ruptura, que escanden esos usos repetitivos de la máquina, que no tienen nada de mecánico.

Un día, para el cumpleaños de nueve de su hermano Walter, Owen se puso a llorar. "Walter no quiere crecer, como Mowgli o Peter Pan", dijo Owen. Comparar a su hermano con personajes de Disney era la cosa más sofisticada que Owen, entonces de seis años, había pronunciado en años. (Harpaz, 2014, s/p)

El recurso a la máquina para dar lugar a la función de la letra en su dimensión de inscripción repetitiva puede ser reducido a un abordaje comportamental. Es el de los investigadores de Yale que intentan establecer una terapia estandarizada a partir de la terapia de afinidad. Describen lo que para ellos es un "juego de roles", cuyo uso hay que alentar por medio de un sistema de recompensa.

Con respecto a esta lógica comportamental, consideremos el punto de vista del terapeuta Dan Griffin, que trabajó durante mucho tiempo con Owen. En una entrevista que mantuvo con Ron Suskind y la periodista Hanna Rosin (también madre de un niño autista), él aísla el momento en que Owen pudo hacer un uso nuevo de los diálogos de Disney, en una perspectiva psicodinámica: 
Dan Griffin: Lo recuerdo hasta hoy. Habíamos hecho una pausa en el curso de la sesión. En general Owen se iba de la habitación rápidamente y ese día permaneció allí. Ustedes interpretaron una escena con Iago (un personaje de Aladdín) creo. Y de repente se produjo una descarga iónica en la habitación. Tú estabas mucho más comprometida. Él estaba mucho más comprometido. Teníamos la impresión de que todo era posible. Había una conexión pura y una alegría pura; y eso hizo nos hizo hacer un click, ¡debemos ser capaces de explotar eso! Ron: Voy a decirte lo que era. Era la escena en la que Iago dice, "Ok, entonces tú te casas con la princesa y pasas a ser el marido idiota". Owen la hizo. $\mathrm{Y}$ yo respondí como Jafar, "Me gusta el modo en que funciona tu cabecita malvada." (Rosin, 2014, s/p)

Lo que Dan Griffin ve como una descarga de energía presente en la habitación parece más bien describir ese punto en el que la recuperación de la voz permite empujar más allá del punto en que Owen soportaba el intercambio, para agrandar su circuito de intercambio. Ese punto de empuje más allá está bien descripto por su madre:

Todos esos niños tienen obsesiones y afinidades. La diferencia es que utilizamos su afinidad como un instrumento, no sólo para entrar en contacto con él, cantando canciones, mirando películas juntos, jugando con personajes y encarnándolos; sino también llevando más lejos el proceso y comenzando a utilizarlo para ayudarlo en sus estudios y en sus relaciones sociales crecientes. (Harpaz, 2014, s/p)

Y Ron describe también muy bien el reverso de esos momentos de energía, la manera en la que Owen domó la enorme carga emotiva de los dibujos animados tratándolos por medio de la pura repetición:

Esos films están basados en temas poderosos, como los de los hermanos Grimm y de los mitos milenarios. Pero es sólo desde la llegada a los hogares de las videocaseteras que los niños como Owen pueden rebobinar y sistematizar el aprendizaje a su propio ritmo, y obtener a partir de esos relatos ricos en emociones cosas que no podían obtener a partir de las interacciones humanas. Owen utilizó las películas para comprender lo que él era y su lugar en el mundo. Se encontraba en la figura del personaje secundario o del compañero [sidekick]. "Un personaje secundario ayuda al héroe a cumplir su destino". Es una idea muy fuerte. Daba identidad de personajes a otros niños de la escuela y decía: "Soy el protector de los personajes secundarios, ninguno de ellos será dejado de lado." (Harpaz, 2014, s/p)

Con la ayuda de las cortinas musicales de Disney, Owen aprende a leer. Pule sus competencias de escritura retrabajando los guiones de los clásicos de Disney. Hablando por medio de las voces de personajes secundarios de Disney, sabios o 
protectores, como Rafiki, el mono mandril de rol secundario en El Rey León, encuentra su camino a través de las historias propuestas por su terapeuta para abordar sentimientos tales como "estar perdido o desorientado, ser engañado, estar frustrado, o perder un amigo." (Warner, 2014, s/p)

Más tarde, Owen pudo ser escolarizado en su domicilio, y finalmente, en una escuela especial para niños autistas.

\section{Las variedades de la letra y el tratamiento de la voz}

Vemos cómo el abordaje de la terapia de afinidad permite hacer variar la instancia repetitiva de la letra. Del mismo modo, la obra de Daniel Tammet da testimonio especialmente de un amor por la materialidad de la letra a través de los números, el trazo, la escritura, las palabras, la voz poética. Sabe conmover a partir de efectos metafóricos que acercan de modo inesperado ámbitos separados. Hace de la metáfora el fundamento de la actividad matemática.

Estos registros, estas facultades que son cantar, hablar, escribir, dibujar, escuchar o tocar música, cada quien se las apropia a su modo y de manera heterogénea en tanto que escritura, cifra, fijación de la palabra, imágenes discontinuas, o por medio de la utilización de la música y de la melodía. Niños totalmente mudos pueden escribir una gran cantidad de cosas, algunas ilegibles, otras legibles. Otros niños no se sitúan ni del lado del habla ni del lado de lo escrito, sino que cantan. Otros únicamente cuentan. Un sujeto puede entonces afirmar: "Me olvidé de todo, yo sólo sé que sé contar". Los diferentes objetos digitales permiten destacar la articulación de estos diferentes registros y lo que tienen en común: la posibilidad de la repetición. Los teclados nos permiten superar las dificultades de la motricidad fina, la que supone una relación con el cuerpo y con su imagen particularmente eficaz de la cual no todos los sujetos pueden beneficiarse.

En la conexión del sujeto autista con el otro observamos el rol de las computadoras, tanto en el procedimiento utilizado por B. Sellin como en el dispositivo de comunicación facilitada inventado por Rosemary Crossley o en la comunicación asistida utilizada por colegas argentinos. El libro de Jean-Claude Maleval, L' autiste, son double et ses objets [El Autista, su doble y sus objetos] (Maleval, 2009), dio cuenta de los usos posibles de las máquinas para anudar un lazo con el sujeto. Ron Suskind le propuso a los fabricantes de programas de reconocimiento vocal SRI (que le dieron su nombre a Siri) que permitieran elegir voces personalizadas de dibujos animados para sus asistentes. Para un niño que habla especialmente con Aladdín la voz del asistente podría ser la de ese personaje, permitiendo así difractar las voces.

En esta repetición, ¿se trata de un juego de roles o de un tratamiento de la voz del Otro? La cuestión se plantea a partir del fenómeno de la ecolalia, cuyo lugar y función activa han sido demostrados. La cuestión también se plantea a partir de otros ejemplos diferentes al de O. Suskind, como el de Tom (Junius, 2015) quien, al 
llegar a los siete años a una escuela especializada, no soporta la clase. Él juega solo, con fragmentos de frases de dibujo animado. Frases descontextualizadas, fuera de sentido, lo atraviesan. Los padres se preocupan al verlo obnubilado por el dibujo animado, por ciertas frases y canciones. Los primeros encuentros con Tom son explosivos, abre cajas, tira objetos al piso, agarra anteojos, prende/apaga la luz, se fija en un reflector halógeno con dos focos de luz dicroica: Tom utiliza uno para mirar su reflejo y con el otro hace un micrófono. Canta y le pide al terapeuta que cante con él. En ese estallido de los circuitos de la voz y de la mirada que no están puestos en forma por medio de una imagen estable del cuerpo, Tom introduce un poco de ritmo. "Golpea el radiador, y todo su cuerpo se pone en movimiento. Se tira al suelo, se esconde bajo la mesa, hace la mímica del 'Sr. Totem' tomando un cofre cuya tapa cierra de golpe como una boca que grita" (Junius, 2015, pp. 16-17). También utiliza frases rituales que le permiten soportar mejor la separación. "Por ejemplo, dice 'gracias, gracias, hasta luego' a los objetos, demasiado vivos, que utilizó durante la sesión y 'gracias, gracias, Justine'. Yo le respondo, 'gracias, gracias, Tom' y nos damos la mano" (Junius, 2015, pp. 16-17).

En el curso del desarrollo de las sesiones, allí donde estaba el grito y la boca gritona aparecen fragmentos de historias con aires catastróficos.

Por ejemplo, grita "Están llegando, vamos, apuren, apuren; mamá, mi hijo, todos al hormiguero!” (...) Intervengo: “Te puedo ayudar Tom?” Él: "No...Sí, mira: alguien quedó atascado en el edificio, abre la ventana para salvar a Flash McQueen y los otros autos" (...) Las frases que Tom repite, tuerce y retuerce, (...) se vuelven más coherentes. Por otro lado, él integra oposiciones significantes aprendidas en clase, tales como "izquierda-derecha", "día-noche", "calor-frío". El año siguiente (...) Tom soporta mejor quedarse en la clase (...) participa en un taller de canto que culmina a fin de año con una muestra en la que seduce a la sala con su desempeño. Cuestiona el lenguaje no solamente con los dibujos animados y las canciones, sino a partir de los enunciados escuchados en la escuela. (Junius, 2015, pp. 16-17)

Puede incluirse con los otros. Su manera de incluirse siempre está ligada a su angustia de exclusión. "Por ejemplo, se ubica frente al docente adulto y le dice 'Estás despedido!', luego vuelve, y pide disculpas...” (Junius, 2015, pp. 16-17). Con una institutriz, "invierte los roles pidiéndole que no cante sino que cuente" (Junius, 2015, pp. 16-17). Es así que ingresará en el sistema de aprendizaje de los números y de las cuentas.

$\mathrm{Al}$ encontrar un enganche en la voz y en el cuerpo de la terapeuta, Tom pudo poner a distancia la explosión que lo amenazaba en el caos equívoco de los diferentes registros pulsionales de goce que poco a poco se organizan en el intercambio y se transforman en una elaboración que, posteriormente, va a permitir un uso 
conversacional del lenguaje.

\section{Variedades de la letra y tratamiento de la mirada}

Después del tratamiento de la voz, pasemos al tratamiento de la mirada del Otro por medio de las reorganizaciones del espacio de la visión, en particular por medio de la reorganización del pasaje de las representaciones de dos a tres dimensiones. Estos pasajes suponen la circulación del sujeto en un espacio topológico deformable. El sujeto, afectado por el encuentro con una lengua, ya sea hablada, escrita o digital, es zambullido en un espacio topológico que no es el de la geometría euclidiana, que no es el del espejo plano. Es un espacio que no se conecta fácilmente con el cuerpo. Los esfuerzos de los sujetos por juntarlos demuestran la importancia de esto. También aquí podemos partir de la terapia de afinidad, ya que el dibujo animado es capturado inicialmente en $2 \mathrm{D}$ en un espacio plano. El niño conecta su cuerpo con la pantalla sobre la cual se proyectan imágenes de diferentes modos. Puede pegarse a la pantalla televisual, o por el contrario apartarse de ella, ocasionalmente darle la espalda.

La relación del campo de la visión con el espacio plano se lleva a cabo de múltiples maneras. Otro ejemplo lo muestra. Un niño con autismo, Jules, tiene pasión por buscar

(...) en Google Earth y Google Maps para visualizar los lugares donde vivió así como su domicilio actual. (...) También realiza búsquedas sobre las pantallas como tal: pantallas de cristal líquido, el tamaño de las pantallas, las pantallas táctiles, las imágenes de las pantallas rotas. Y luego, hay búsquedas sobre 3D: las impresoras 3D, los televisores 3D, las tablets 3D, las películas 3D. "Me gusta el 3D porque no se ve la punta." (Louis, 2015, pp. 21-22)

Su interés por el 3D también se desplaza "a la cifra 3: el auto Citroën C3, el triángulo" (Louis, 2015, pp. 21-22). Le dice a su educador:

\footnotetext{
"Tienes una cabeza en triángulo" [...] también hay "biberones triángulos" que lo acompañaron hasta sus ocho años. "El 3D, es su biberón triángulo, su obsesión del momento", dirá su padre. Todas sus búsquedas en la computadora terminan casi invariablemente con un golpe de puño de Jules sobre la pantalla. "Boom, boom. ¿Cuándo puedo romper la computadora? ¿Por qué no se la puede romper? ¿Está prohibido? ¿Es una pequeña o una gran estupidez?” (Louis, 2015, pp. 21-22)
}

Para Jules, el intento de incluir su cuerpo en la pantalla no consiste en pegarse a ella sino en atravesar el espejo. El golpe de puño final apunta a incluirse en el campo de su visión. No deja de proponer:

(...) construcciones en cartón a las que les asigna sistemáticamente el calificativo '3D'. Para cada realización, Jules se ocupa largo tiempo en el trazado de los planos 
que compila en un cuaderno. Traza meticulosamente sus modelos según diferentes perspectivas, vistas de arriba, de frente, vista lateral. (...) Pone en escena (...) camiones monstruos que aplastan pequeños vehículos que se despedazan contra las paredes - dibujar rutas, circuitos viene a bordear el estallido. (Louis, 2015, pp. 21-22).

En la destrucción contra las paredes vemos un modo de aplastamiento de la representación del objeto y del cuerpo:

Él se preocupa más en elegir los colores, los papeles para vestir sus creaciones. [...] Comenzó con los decorados que denominó 'los decorados vacas'. Se trata de estampados con las manchas características [del pelaje] de las vacas. Hay que decir que la leche de vaca le interesa mucho en su vida cotidiana. Habiendo constatado que estaba mucho más agitado al terminar sus comidas, los padres de Jules pusieron eso en relación con el consumo de productos lácteos y desde entonces los suprimieron de su alimentación. Desde entonces, Jules no deja de abrir las heladeras de la institución para agarrar cajas de leche que aplasta. (Louis, 2015, pp. 21-22)

El taller de los "decorados vacas" permitió que no se pasara todo el tiempo abriendo la heladera. La deformación del espacio le sirvió también para orientarse en los equívocos del lenguaje. Durante una época, estuvo muy intrigado por el equívoco de privado, entre "está reservado para él" y está "privado de". Durante este período elaboró un objeto-habitáculo particular, "un helicóptero bicolor. Pega las dos caras del helicóptero diciendo 'lo vamos a llamar un helicóptero privado 3D' para remarcar su búsqueda" (Louis, 2015, pp. 21-22). El lógico Austin escribió un bello libro cuyo título era Cómo hacer cosas con palabras (Austin, 1962). Aquí es a la inversa: se trata de hacer las palabras, de darles un sentido "privado" fabricando cosas. Es a partir de cosas que Jules fabricó un nuevo uso conversacional de las palabras.

Esta fábrica de cuerpos y de palabras conlleva también enganches con imágenes tomadas aleatoriamente de los recursos disponibles, que incluyen siempre más imágenes. Nos permite comprender cómo el sujeto puede desplazarse en el mundo e interrogarlo a partir de un uso privado de la lengua común.

\section{La repetición, lalengua, lo escrito}

Estos modos de tratamiento de los circuitos de la voz y de la mirada suponen el encuentro del sujeto con autismo con una lalengua en el baño de lenguaje en el que está sumergido. Y este encuentro es muy particular. Pasa por el balbuceo: los estudios convergen en establecer su pobreza y su falta de orientación social (Maleval, comunicación personal). La ausencia de balbuceo, la ausencia de equívoco lenguajero encarnado está presente desde el inicio de los estudios sobre el autismo. Por el contrario, hay repetición de algunas palabras/cosas. 
Finalmente, se constata la presencia del significante puro. El significante como tal es tonto. Se presenta así, es un puro cifrado y cifra todo. Además, este cifrado es autoerótico. Hay para el niño un goce particular en cifrar así, que no está para nada centrado en el intercambio con el otro. Ese significante puro no se dirige. J.-C. Maleval subraya ese punto:

Durante los primeros meses algunos autistas no vocalizan, sino que lloran o gritan cuando están despiertos. Otros permanecen en silencio. Cuando el balbuceo existe, lo más frecuente es que aparezca como algo monótono (comparable al de un bebé con mucho sueño), sin espíritu, sin inflexión intencional. Además, no se adapta a las producciones maternas. Algunos autistas balbucean en soledad pero se interrumpen en presencia de un padre. (Maleval, comunicación personal).

Este modo de surgimiento de lalengua no se dirige, pero deja marcas sobre el cuerpo, lo afecta. Este modo de afectación traduce la inscripción de la marca de goce sobre la superficie del cuerpo, por el modo mismo de repetición. Si los niños autistas no se articulan a la función de la palabra, no por eso son insensibles a la instancia de la letra, ya que los sujetos autistas que presentan un retraso en la adquisición del lenguaje hablado disponen de lo escrito. B. Sellin le escribe a otro autista, "simplemente deseo, como tú, poder invertir mis instrumentos orales en el lenguaje. Pero sigo vagando lejos del lenguaje” (Sellin, 1998, p. 130).

La expresión brutal de B. Sellin reenvía a un punto que Lacan destaca desde el inicio de su enseñanza. El Otro y la voz no se articulan en ningún sensorium en particular, sino más bien en el cuerpo como tal. En el Seminario X, La Angustia, retomando su Seminario I, Lacan enuncia: "hay vías distintas que las vocales para recibir el lenguaje. El lenguaje no es vocalización. Vean ustedes a los sordos" (Lacan, 2006, p. 296). Ya había utilizado el ejemplo de los sordos en el Seminario III sobre Las Psicosis:

Es todavía más simple si pensamos en el sordomudo, quien es capaz de recibir un discurso a través de signos visuales realizados con los dedos [...] Diría aún más, lo que registra, a saber la sucesión de esos signos, su oposición sin la cual no hay sucesión, ¿̨podemos decir en sentido estricto que la ve? (Lacan, 1984, p. 197).

Al igual que en el primer seminario donde, gracias a San Agustín, había cortado el lazo entre el sensorium de la voz y la cuestión del intercambio de signos, corta aquí el lazo con la visión. No considera que la cadena significante de los signos "se vea", hablando con propiedad. Se percibe más allá de todo sensorium. Podría decirse que es el cuerpo en toda su superficie el que está movilizado. El lenguaje impacta más allá 
de los sensorium concernidos. Lo que se percibe más allá de todo sensorium es la oposición, dice el primer Lacan. Podríamos completar esto con el último Lacan, diciendo que se trata de la repetición como tal.

Laurent Mottron, investigador canadiense que rechaza el psicoanálisis pero que dice cosas sensatas sobre el autismo, retoma esta línea de investigación:

Mientras que se encuentra muy retrasado en el lenguaje oral, [el sujeto autista] es precoz respecto del código escrito. Este interés se produce por fuera de toda intención comunicativa, como en el caso de la ecolalia diferida en sus inicios [...] El lenguaje escrito permite un abordaje no social del lenguaje. (Mottron, 2016, citado por Maleval, comunicación personal).

El lenguaje no está hecho para comunicar. El lenguaje inscribe experiencias de goces, repetitivas. Las trazas del impacto del lenguaje sobre el cuerpo, al no poder conectarse con lo fonético [à la phone], se inscriben sobre el cuerpo en lugares extraños que definen una topología particular de la voz. La voz puede estar dentro del cuerpo o ser vivida también como un exterior, un fuera-del-cuerpo, que puede ser imaginariamente localizada en un órgano externo, una "voz artificial". Como hemos visto, instrumentos de música, micrófonos, marionetas, dobles y objetos diversos pueden ser convocados con este fin.

\section{La repetición y el lenguaje privado}

El rechazo de utilizar la lengua común hablada y la relación privilegiada con lo escrito se acompaña sin inconvenientes por la existencia de un lenguaje privado, como "elucubración de saber" sobre la lengua común. No está hecho para comunicar. Valérie Gay-Corajoud notó que hacia los tres años y medio su hijo Théo inventó una lengua neológica que su entorno llegó a comprender. Sus seres cercanos se pusieron entonces a hablar con él en esta lengua. Sin embargo, desataca su madre, se negó a "que utilizáramos su lenguaje como respuesta. Debimos continuar hablándole habitualmente y él nos respondía con su lenguaje reinventado" (Gay-Corajoud, 2018, p. 95). Este lenguaje intenta evitar los equívocos de lalengua común. Es un intento de asignar designaciones tan unívocas como sea posible.

El ejemplo de la lengua inventada por D. Tammet me parece responder a la misma voluntad de extracción de un lenguaje unívoco a partir del impacto de lalengua sobre el cuerpo. Desde su pequeña infancia, adopta el lenguaje de los números, pero los números tienen un extraño impacto sobre su cuerpo. Él posee una percepción sinestésica de cada uno de estos, de modo que se le aparecen "tanto como formas, colores, texturas y movimientos. El número 1, por ejemplo, [escribe él] es un blanco brillante y vibrante, como alguien que dirige el haz de luz de una linterna directamente hacia mis ojos" (Tammet, 2009, p. 11). Cada elemento-número resulta en un lenguaje gracias a esta combinación inédita de forma y de emoción que hace del número un objeto complejo, equívoco desde el punto de vista de la referencia. 
Como en el caso del Uno, en el que el número se encuentra ligado a la intrusión de una linterna que apunta hacia los ojos.

Esta lengua privada está cargada de un goce excepcional y le procura intensas emociones. "Esta dimensión estética de mi sinestesia tiene sus lados buenos y malos" (Tammet, 2009, p. 15) entre "escalofríos de excitación y de placer" y "me irrita y me pone incómodo". No son exactamente afectos, sino acontecimientos del cuerpo que se producen.

La conferencia brindada en el Espacio de Ciencias de Rennes en 2018 (Tammet, 2018) nos permitió, en respuesta al pedido de una espectadora, escuchar a D. Tammet recitar un poema de números que había compuesto. La emoción pura fue evidente, pero permaneció obscura para el auditorio - como él mismo señaló. Ya de adolescente aquello no fluía. Esta lengua materna de números continúa siendo opaca: a pesar de ser depositaria de experiencias emocionales intensas, no está conectada con el otro.

Con su otra lengua privada, el Mänti, reencontramos la misma intención de eliminar el equívoco, lo discordante de la lengua común para alcanzar un referente preciso. El Mänti permitía "encontrar palabras para expresar mis experiencias particulares. A veces, cuando sentía una emoción particularmente fuerte, si tenía la experiencia de algo extremadamente bello, una palabra nueva se formaba espontáneamente en mi espíritu para expresarla y no sabía de dónde podía venir. Por el contrario, a menudo me parecía que la lengua de mis camaradas era confusa y discordante" (Tammet, 2009 , p. 216). Esta operación original de nominación resultó para D. Tammet tan eficaz como la que apuntan a lograr los anteojos Google para ayudar a los sujetos autistas a nombrar emociones, acoplando programas de reconocimiento facial con etiquetas de emociones. Revela también que este etiquetado involuntario es hecho por esa máquina fundamental que hay en nosotros que es el lenguaje, del que no sabemos de dónde proviene.

Este lenguaje privado pretende ser exacto: "Continué soñando con el día en que hablaría una lengua bien mía... y que esta expresaría exactamente algo de mí mismo" (Tammet, 2009, p. 216). Por otro lado, es una elucubración de saber: "Intento inventar en Mänti palabras que establecen otros lazos entre las cosas: hamma (diente) y hemme (hormiga-un insecto que muerde-), rât (cable eléctrico) y ratio (radio), por ejemplo" (Tammet, 2009, p. 217). Durante esta conferencia, D. Tammet destacaba que no tenía más necesidad de pasar por su lengua inventada ahora que se había convertido en escritor y que había forjado su lengua propia en sus libros. En este sentido, lejos de ser una "barrera autística más para la comunicación", como algunos dicen, el lenguaje privado constituye más bien un borde transitorio, hasta que pierde su especificidad. Karim Nazeer da cuenta de la curiosa facilidad para aprender lenguas reputadas como complejas por el hecho de que "en éstas hay tantas reglas y estructuras que eso elimina los equívocos que plantean problemas a los autistas. Un sentido/una palabra sería para ellos el ideal" (Nazeer, 2007, p. 26).

Podemos oponer a la construcción de una lengua privada el surgimiento de 
vocalizaciones involuntarias, como las que atraviesan a Temple Grandin en ocasión de un accidente de auto sucedido en su pequeña infancia cuando todavía estaba en mutismo:

Mamá intentó girar el volante, recuerda ella, pero era demasiado tarde. Escuché el golpe del metal y sentí el choque violento.... Grité 'espejo, espejo' mientras el vidrio roto llovía sobre mí. No tuve miedo para nada. Fue bastante apasionante. (Grandin, 1997, p. 39)

En el momento de la mayor amenaza surge una vocalización que designa el vidrio que se rompe. "A veces pronunciaba palabras, como lo había hecho con el espejo, muy claramente. Esto ocurría durante momentos de gran tensión como el accidente de auto, cuando el stress llegaba a vencer la barrera que normalmente me impedía hablar" (Grandin, 1997, p. 39). La originalidad de esta emoción es la de un stress, pero sin miedo experimentado. Que la palabra que surge tenga relación con el espejo que se rompe no deja de tener interés.

También está la primera frase pronunciada por B. Sellin: "devuélveme mi pelota", dirigida a su padre que venía de sacarle uno de sus objetos autísticos (Sellin, 1994, p. 24). ¿Se trata de una "palabra automática", o del testimonio de una imposibilidad de entrar en el lenguaje por la vía de la palabra, pero que se sitúa en los márgenes de un fenómeno entre la letra y la palabra? En la última enseñanza de Lacan, esos fenómenos de borde son llamados jaculaciones. En la serie de las jaculaciones, intenta inscribir la interpretación psicoanalítica del lado de algo que está más allá de la palabra, una mezcla de la palabra y lo escrito. En este más allá de la palabra, Lacan ubica tanto las jaculaciones, los gritos del maestro Zen, como los efectos emocionantes obtenidos por la poesía.

En estos diferentes campos, desde el balbuceo hasta la jaculación disruptiva, pasando por la invención de un lenguaje privado, este arreglo da cuenta de una subjetividad autística que se produce en la construcción del lenguaje privado como siendo el testimonio por excelencia de la construcción de un borde específico entre el sujeto y el Otro con el cual se las tiene que ver. Estos fenómenos originales atestiguan acerca del encuentro con el baño de lalengua en el cual el sujeto es sumergido, en todas sus variedades. El sujeto se extrae de lalengua común apoyándose en la repetición de la inscripción de las palabras sobre el cuerpo. El sujeto no está hecho para comunicar, sino para insertarse en el mundo de manera autoerótica. Y son los circuitos que el sujeto compondrá los que le permitirán obtener esta inclusión en el mundo. La cura de Louange, el niño del armario, comentada por J.-C. Maleval y Michel Grollier, lo muestra de un modo destacado (Maleval y Grollier, 2019). Por medio de las vías de la creación, la obra de D. Tammet es un ejemplo, hoy conocido por todos, de construcción de una lengua particular, largamente elaborada, por un proceso que lo volvió sensible a lo que escapará de la máquina y del "Test de Turing”. 


\section{Notas}

${ }^{1}$ La presentación de ese libro tuvo lugar en Francia en la Universidad Rennes 2 durante el Coloquio Internacional "Affinity therapy: una nueva mirada sobre el autismo", el 5 y 6 de marzo de 2015. R. Suskind y D. Griffin son los creadores del término affinity therapy.

\section{Referencias}

Austin, J. L. (1962). How to do things with words. Harvard University Press.

Chérel, M. (2019). Argument du Colloque "Autisme: Numérique et Robotique. Quel partenaire privilégié au 21e siècle?". Université Rennes 2, 7 y 8 de noviembre de 2019. HTTPS://WWW.LAIREDU.FR/ COLLECTION/COLLOQUE-AUTISME-NUMERIQUEET-ROBOTIQUE-QUEL-PARTENAIRE-PRIVILEGIEAU-21E-SIECLE

Gay-Corajoud, V. (2018). Nos mondes entremêlés Imprim'vert.

Grandin, T. (1997). Ma vie d'autiste. Odile Jacob.

Harpaz, B. J. (2014). A little movie magic: How Disney films unlocked an autistic boy's emotions. Entrevista con R. y C. Suskind, 26 de marzo de 2014. AZcentral. HTTPS://EU.AZCENTRAL.COM/ STORY/ENTERTAINMENT/BOOKS/2014/03/26/ DISNEY-FILMS-AUTISTIC-BOY-EMOTIONS/6913067

Junius, J. (2015). Apprendre et se laisser apprendre Quarto, 111, 16-17.

Lacan, J. (1984). El seminario. Libro III. Las psicosis. Paidós.

Lacan, J. (2006). El seminario. Libro X. La angustia. Paidós.

Laurent, É. (2012). La bataille de l'autisme. Navarin/Le Champ Freudien.

Louis, S. (2015). Tentatives pour se faire partenaire. Quarto, 111, 21-22.

Maleval, J. C. (comunicación personal). De l'aliénation retenue chez lautiste. Comunicación personal, de pronta publicación.

Maleval, J.-C. (2009). L'autiste, son double et ses objets. Presses Universitaires de Rennes.

Maleval, J.-C. y Grollier, M. (2019). Une démonstration éblouissante. Un enfant autiste en analyse. Lacan Quotidien, 831, 12 de abril de 2019.
HTTPS://www.LACANOUOTIDIEN.FR. Traducido al español en HTTPS://WWW.WAPOL.ORG/ES/GLOBAL/ LACAN-QUOTIDIEN/LQ-831-BAT.PDF

Metz, C. (2019). Google Glass for autistic children. The New York Times, 17 de julio de 2019.

Mottron, L. (2016). L'intervention précoce pour enfants autistes. Mardaga. [Citado por J. C. Maleval, comunicación personal]

Nazeer, K. (2007). Laissez entrer les idiots. Témoignage d'un autiste. Seuil.

Newman J. (2014). To Siri, with love. The New York Times, 17 de octubre de 2014.

Reliquet, S. y Reliquet, Ph. (2011). Écouter Haendel. Gallimard

Rosin, H. (2014). A pathway, not a prison. Entrevista con R. y C. Suskind. Slate, 1ro de abril de 2014. HTTPS://SLATE.COM/HUMAN-INTEREST/2014/04/ LIFE-ANIMATED-TALKING-ABOUT-AFFINITIESAU TIS M - AND - DISNEY - WITH - RON - SUSKINDCORNELIA-SUSKIND-AND-DAN-GRIFFIN.HTML

Sellin, B. (1994). Une âme prisonnière. Robert Laffont.

Sellin, B. (1998). La solitude du déserteur. Robert Laffont.

Suskind, R. (2016). Life, animated: A story of sidekicks, heroes, and autism. Hyperion.

Tammet, D. (2009). Je suis né un jour bleu. J’Ai Lu.

Tammet, D. (2018). Chaque mot est un oiseau à qui l'on apprend à chanter. Conferencia, Espacio de Ciencias, Rennes, 16 de enero de 2018.

Warner, J. (2014). A family's hard journey, with Disney as a guide. The New York Times, 21 de mayo de 2014. HTTPS://WWW.NYTIMES.COM/2014/05/22/ BOOKS/LIFE-ANIMATED-BY-RON-SUSKIND.HTML 